\title{
The Relationship between the Arrangement of Constituents and Reading Speed
}

\author{
Zahra Jokar \\ Shiraz University, Iran \\ Seyyed Mohammad Ali Soozandehfar \\ Shiraz University, Iran \\ Email: soozandehfar@yahoo.com
}

\begin{abstract}
The purpose of this study was to investigate the relationship between the arrangement of constituents and reading speed. This study answered this question: "does the arrangement of constituent affect reading speed?" The subjects of the study were 30 female EFL graduate students at Isfahan University. Two forms of a passage were used. One form (form A) with breaks between constituents and one intact form (form "I"). These forms were given to two homogenous groups. To achieve two homogenous groups, Oxford Placement Test 1B1 (Allan, 1985) was administered. Finally, the data of Placement test scores was analyzed through Mann-Whitney test. An Independent sample t-test was used to analyze the data of time of reading comprehension of the two groups. The results of t-test proved that there was significant difference $(0.03)$ between the times of reading comprehension of the two groups. The subjects in the group (I) spent less time in accomplishing the test than that in another group. The main finding of the study was that arrangement of the sentences in a passage may affect reading speed. It was preplanned to write a program to design a type of software to record the exact time of the reading speed and answering the multiple-choice questions but because of lack of time, the participants used stop watches of their cell phones to measure spent time.
\end{abstract}

Index Terms — constituents' arrangement, reading speed, reading, constituent

\section{INTRODUCTION}

Reading ability is recognized as critical for academic learning. Interest in second language reading research and practice has increased dramatically in the past 15 years. Little attention has been attached to considering the role of constituents' arrangement in speed of reading comprehension. A study by Graf and Torrey (1966) proved that isolated constituents help to comprehend faster. What these researches and findings suggest is that constituents play an important role in reading comprehension speed. This study tries to investigate whether special text arrangement can affect readers' perception speed. Because reading is one of the four skills taught in almost every language, teachers of English may benefit from the results of this study.

\section{LITERATURE REVIEW}

One of the most important information processing skills is reading comprehension. Many components of reading are unconscious and process of reading comprehension is highly automatic. William James anticipated the contemporary distinction between working and long-term memory, which he called primary and secondary memory, in his landmark book, principles of psychology (James, 1890/1950).

\section{A. Short-term Memory}

Short-term memory is the place that new information must remain for a minimum of 20-30 s and after this time, the information will be lost. It is thought that short-term memory is analogous to consciousness and has been described as the "working memory". Psychologists believe that exact wording is stored for a brief period in short-term memory. Clark and Clark (1977) refer to the limited capacity of short-term memory and this part of the brain stores only about seven or so unrelated words at a time (Clark and Clark, 1977).

In an early and highly influential article, The Magical Number Seven, Plus or Minus Two, ${ }^{[13]}$ the psychologist George Miller suggested that human short-term memory has a forward memory span of approximately seven items plus or minus two. For example, if the number 833231893 is presented and you are asked to recall it in the same order, individually, you will face difficulty. You can recall them when you divide the numbers into 3-digit numbers (e.g. 833231-893).

\section{B. Long-term Memory}

Alongside working memory, the information stores of long-term memory are also of importance in learning through reading and reading comprehension. Long-term memory in turn effects through its contents and organized structure the 
ability to understand the applied language and its abstractness as well as pragmatic and other meanings of language. Numminen (2002) found that One major problem with reading comprehension among learners of the Finnish language is thinness of information in long-term memory concerning the studied language. Just \& Carpenter (1992) believes that information from the text and nformation retrieved from long term memory must be temporarily kept in memory to be integrated with newly incoming information while further portions of the text are processed. Ericsson and Kintsch (1995) found that the information is stored in the long term memory during reading.

\section{Reading Process and Constituent Structure}

Phrase structure rules specify the permissible sequences of constituents in a language. The surface structure of a sentence divides up into phrases and sub phrases called constituents. A constituent can be defined as: a group of words that can be replaced by a single word without a change in function and without doing violence to the rest o the sentence" (Clark \& Clark 1997 pp.47-48). Hashemi (1988) found that constituents structure of the text make it more difficult or easier to read. Hyona \& Pollatsek, (1998); Pollatsek, Hyona, \& Bertram (2000) revealed systematic effects of the properties of both the whole words and theirconstituents, with the effects of the first constituentsappearing earlier than those of the whole word or second constituents. McElree (2006) states that sentential constituents (e.g. arguments) should be maximally distinct from one another, so as to avoid interference. McElree (2000) examined what effects interpolated material had on the speed and secondarily the accuracy of processing nonadjacent constituents. No comparable effect was found in the study reported in McElree (2000). McElree (2000) found that the amount of material interpolated between two constituents (e.g., NP and verb) decreased the accuracyof discriminating acceptable from unacceptable relationsbetween the constituents.

\section{Reading and Eye Movements}

During reading, the visual properties of the text are encoded via a series of eye movements (Rayner, 1998), generally from left-to-right across the line of text. Encoding the visual information during fixations typically lasts about 200-250 $\mathrm{ms}$ (though the range is from $50 \mathrm{~ms}$ to over $500 \mathrm{~ms}$ ). The movements of the eyes between the fixations, saccades, typically last 20-30 ms; no new information is obtained during these movements. Indeed, vision is suppressed during saccades (Matin, 1974). On average, the eyes move 7-8 letter spaces (though the range is from a single letter space to over 20 spaces) for readers of English and other alphabetic writing systems; letter spaces, rather than visual angle, are the appropriate measure for indexing how far the eyes move during reading (Morrison and Rayner, 1981). On about 10$15 \%$ of the saccades, regressions, readers move their eyes backwards in the text to look at material that has received some prior processing. Readers tend to increase fixations durations and regressions when text difficulty increases.

\section{E. Word Space and Reading Comprehension Speed}

The spaces between words in English appear to be important in reading because they serve to visually delimit words in the text and, as a result, appear to aid readers (Pollatsek \& Rayner, 1982; Rayner \& Pollatsek 1996). Epelboim et al. (1994) claim that unspaced text is relatively easy to read. In the Spragins et al. (1976) study, reading rate decreased by an average of $48 \%$ when the text was unspaced. A similar finding was reported by Morris, Rayner and Pollatsek (1990). Pollatsek \& Rayner (1982) and Rayner \& Pollatsek (1996) agree that elimination of space informa tion interferes with word identification processes.

\section{METHOD}

\section{A. Participants}

This study was conducted with an overall number of 30 female EFL graduate students at Isfahan University. The participants ranged in age from 25-27.

\section{B. Instruments}

To have two groups of learners with different proficiency level, Oxford Placement Test 1B1 which is a standard test including 50 multiple choice items identifying and assessing the learners' level of English Proficiency (Allan, 1985) was administered. The validity and reliability of the questionnaire is taken for granted.In order to conduct a study, the participants were asked to read two forms of a single text. Each text was followed by five multiple-choice questions. The participants used stop watches of their cell phones to record the time spent on reading the passage and answering the multiple-choice questions.

\section{Data Collection Procedure}

The scoring of Oxford Placement Test was based on the number of items answer correctly by the students. Each correct answer received one point and the total score of the test was 50. After dividing the participants into two groups, they were given two forms of a single text in which they were required to measure total time of the reading and answering multiple-choice questions. One passage was typed out in two forms: Form "A" consisting of non-broken constituents and Form "I" which was kept intact as the original texts. The experiment was of paper and pencil caliber. It was preplanned to use a type of software to record the time of reading speed and answering the multiple-choice questions but because of the lack of time, the participants used stop watches of their cell phone. 


\section{Data Analysis Procedures}

After collection, scores of Oxford Placement Test were entered into SPSS for analysis. To have two homogenous groups, Mann-Whitney test was conducted. Differences between the means of the subjects' reading comprehension time were obtained through the independent sample t-test.

\section{RESULTS}

The Subjects of the two groups were homogenous and the passage as well as multiple-choice questions was identical. The only factor that distinguishes the groups was the preplanned constituents at the line shifts. The results of mannwhitney test showd that the significance of difference of Oxford Placement Test scores was .539, so participants of this study did not differ in terms of their placement test scores. They are homogenious in English language proficiency level.The following is the descriptive statistical analysis of Oxford Placement Test scores.

TABLE1:

\begin{tabular}{lllllll} 
& \multicolumn{5}{c}{ THE DESCRIPTIVE STATISTICS OF PlACEMENT TEST SCORES } \\
& $\mathrm{N}$ & Range & Minimum & Maximum & Mean & Std. Deviation \\
\hline Group 1 & 15 & 10.00 & 40.00 & 50.00 & 44.6667 & 3.28778 \\
Group 2 & 15 & 11.00 & 39.00 & 50.00 & 45.3333
\end{tabular}

An Independent sample $\mathrm{t}$-test showed a significant main effect $(\mathrm{t}=3.64 ; \mathrm{P}<0.05)$ of changing constituents arrangement on the reading speed (see Table 2).

TABLE 2:

\begin{tabular}{lcccc}
\multicolumn{5}{c}{ SUMMARY OF MEAN, STANDARD DEVIATION AND SIGNIFICANCE OF THE READING SPEED OF TWO GROUPS } \\
Text Form & $\mathrm{N}$ & Mean & Std. Deviation & Significance \\
\hline Spaced & 15 & 1.66 & 53.59 & 0.03 \\
Unspaced & 15 & 1.09 & 28.83 &
\end{tabular}

\section{DISCUSSION}

The main question was asked in this study was whether arrangement of constituent can affect reading comprehension speed. The results of t-test proved that there is significant difference between times of reading comprehension of the two groups. The subjects in the group (I) spent less time in accomplishing the test than that in another group. The principal finding of this study is that arrangement of constituent is an effective factor in decreasing or decreasing reading comprehension speed. This result indicates, in agreement with Rayner et al.(1996), that reading time is slower when arrangement of the constituents was chaned.Results of this study is not consistent with Epelboim et al. (1994) who claim that text with changed arrangement is relatively easy to read and it is relatively unimportant for guiding eye movements.he study of reading is one of the oldest topics in experimental psychology; and some of the earliest investigators discovered that it was effective to examine role of eye movements during the reading process.Modern technology must be used in order to examine eye movements. Changing physical arrangement of the constituents can affect fixation time as one of the main contributors to the overall reading rate.

\section{CONCLUSION AND IMPLICATIONS}

In conclusion, the role of constituent arrangement on reading speed was considered. In particular, it has been argued that changing constituent arrangement can make reading speed faster and easier. Two forms of a passage were used. One form (form A) with breaks between constituents and one intact form (form "I"). These forms were given to two homogenous groups. The participants used stop watches of their cell phones to record the time spent on reading the passage and answering the multiple-choice questions. The results of this study examined that arrangement of the constituents can make a text easier or more difficult and make a reader reads a text faster or slower. It was revealed that the subjects in the group (I) spent less time in accomplishing the test than that in another group. Recent studies have been described to show that unspaced texts and constituent arranegement of the text can affect reading speed. It was also noted that fixation duration varies with both the difficulty of the content and the skill of the reader. It should be noted, though, that lack of modern technology can affect study results.It had been planned to use a suitable software to measure the exact time of the reading but the lack of enogh time led to use of a chronometer The lack of capacity to monitor these eye movements to examine the role they may play in reding speed and process can decrease accuracy of the study data. Finally, the findings in this study will be of pedagogical importance. The issue will be of importance to second language teachers of English to familiarize their students with text structures.

\section{LIMITATIONS OF THE STUDY}

There are several limitations attached to a study of this kind. The restriction on the sample of participants is the principal limitation of this study. The participants were a small group of EFL graduate learners. Because of the lack of 
time to prepare a type of software to measure the exact time of the reading, as mentioned, a stop watch of cell phone was used to record the time spent on reading the passage and answering the multiple-choice questions.

\section{REFERENCES}

[1] Allan, D. (1985). Oxford Placement Test 1B1. Oxford University Press.

[2] Clark, H.H., \& Clark, E.V. (1977). Psychology and Language: An Introduction to Psycholinguistics. New York: Harcourt Brace Jovanovich.

[3] Epelboim, J., Booth, J. R., \& Steinman, R. M. (1994). Reading unspaced text: implications for theories of reading eye movements. Vision Research, 34, 1735-1766.

[4] Ericsson, K. A., \& Kintsch, W. (1995). Long-term working memory. Psychological Review, 102, 211-245.

[5] Graf,R., \& Torre, J.W.(1966). Perception of phrase in written language.American Psychological Association Convention Proceedings. pp.83-84.

[6] Hashemi, M.R. (1988). On the notion of psychological reality of constituent structure and its implications in comprehension. An Unpublished M.A thesis.Tehran: Tarbyat Moddarreess University.

[7] Hyona, J., \& Pollatsek, A. (1998). Reading Finnish compound words: Eye fixations are affected by component morphemes. Journal of Experimental Psychology: Human Perception and Performance, 24,1612-1627.

[8] Jafari Gohar, M., \& Ashrafoloqalaee, A.R. (1996). The role of Constituents arrangement in English reading comprehension and speed.Paper presented at 1996 Annual Conference, Tehren.

[9] James, W. (1950). Principles of psychology (Vol. 1).New York: Holt. (original work published 1890).

[10] Just, M.A., \& Carpenter, P.A. (1992). A capacity theory of comprehension: Individual differences in working memory. Psychological Review, 99, 122-149.

[11] Matin, E. (1974). Saccadic suppression: a review. Psychological Bulletin, 81, 899-917.

[12] McElree, B. (2006). Accessing recent events. In: Ross, B.H. (Ed.), The Psychology of Learning andMotivation, 46. Academic Press, San Diego,CA, pp. 155-200.

[13] McElree, B. (2000). Sentence comprehension is mediated bycontent-addressable memory structures. Journal of Psycholinguistic Research, 29, 111-123.

[14] Morrison, R.E., \& Rayner, K. (1981). Saccade size in reading depends upon character spaces and not visual angle. Perception \& Psychophysics, 30, 395-396.

[15] Morris, R. K., Rayner, K., \& Pollatsek, A. (1990). Eye guidance in reading: the role of parafoveal letter and space information. Journal of experimental Psychology. Human Perception and Performance, 16, 268-281.

[16] Numminen, H (2002). Working memory in adults with intellectual disability. Famr, Research Publications 85/2002. Helsinki: Kehitysvammaliitto.

[17] Pollatsek, A., Hyona, J., \& Bertram, R. (2000). The role of morphological constituents in reading Finnish compound words. Journal of Experimental Psychology: Human Perception and Performance, 26, 820-833.

[18] Pollatsek, A., \& Rayner, K. (1982). Eye movement control in reading: the role of word boundaries. Journal of Experimental Psychology: Human Perception and Performance, 8, 817-833.

[19] Rayner, K., (1998). Eyemovements in reading and information processing: 20 years of research. Psychological Bulletin,124, $372-422$.

[20] Rayner, K., \& Pollatsek, A. (1996). Reading unspaced text is not easy: comments on the implications of Epelboim et al.'s (1994) study for models of eye movement control in reading. Vision Research, 33, 461-465.

[21] Spragins, A. B., Lefton, L. A., \& Fisher, D. F. (1976). Eye movements while reading and searching spatially transformed text: a developmental examination. Memory \& Cognition, 4, 36-42.

Zahra Jokar is a Ph.D candidate in TEFL. He got her BA in English Language Translation and her MA in TEFL from Shiraz University.

Seyyed Mohammad Ali Soozandehfar is a Ph.D candidate in TEFL. He got his BA in English Language and Literature and his MA in TEFL from Shiraz University. 